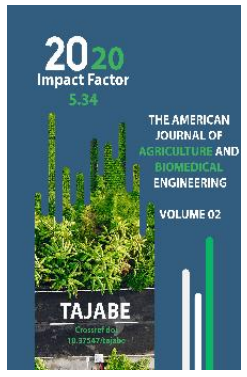

\title{
Pest Control Measures On Mung Bean
}

\author{
Shakhnoza Makhmudova \\ Tashkent State Agrarian University, Uzbekistan \\ Mokhichekhra Ablazova \\ Tashkent State Agrarian University, Uzbekistan
}

Copyright: Original

content from this work may be used under the terms of the creative commons attributes 4.0 licence.

\section{ABSTRACT}

Treating seeds of leguminous crops against bruchuses 20 days before sowing with insecticide dressing agents at the rate of consumption of Avalanche $70 \% \mathrm{~d} .4 \mathrm{heg} / \mathrm{t}$ and Cruiser Extra Cotton 362 c.t., $3 \mathrm{I} / \mathrm{t}$ at the end of the growing season preserves up to $45-50 \%$ yield.

\section{KEYWORDS}

Leguminous crops, mung bean, kernels, harmfulness, insecticide dressing agents, biological effectiveness, chemical treatment.

\section{INTRODUCTION}

Legumes, like other agricultural crops, are highly infested with various pests. Among these pests there are specialized and polyphages. Basically, specialized pests do more harm than polyphages. Legumes also have such pests and one of them is caryopses -
Bruchidae. According to the literature data, mung harvest during the growing season and during storage in warehouses contaminates up to $50-60 \%$ with this pest $[1,2]$.

Currently, the development of measures to combat the above-mentioned pests is the 
main task, and during 2017-2019 we carried out research work in this direction.

\section{RESEARCH METHODOLOGY}

Testing of drugs (insecticide dressing agents) against caryopsis on leguminous crops was carried out in farms of Tashkent oblasts. At the same time, the seeds of beans, mung bean and chickpea were treated with preparations 15 days before sowing at the Avalanche consumption rate of $70 \% \mathrm{dp} .4 \mathrm{~kg} / \mathrm{t}$ and Cruiser Extra Cotton 362 class sous. Experiments and calculations of efficiency were carried out according to the generally accepted method. [3.4]. In order to determine the infestation of the obtained crop, 5000 seeds were examined and analyzed from each variant.

\section{RESEARCH RESULTS}

During the years of research, we determined the infestation up to $60-70 \%$ of the yield of mung crops with caryopses during the growing season and during storage.

Biology. Caryopsis (Bruchidae) is a highly mobile insect in hot and daylight hours. In spring, these pests often and strongly infest late-sown leguminous crops in the flowering phase and bean formation. The beetles of these pests feed on the nectar of mung flowers [4]. In the conditions of Uzbekistan, there are 3 types of weevils - pea weevil (Bruchus pisarum L.), four-point weevil (Callosebruchus maculates Z.) and bean weevil - (Acanthoscelides obsoletus Say.). According to the data, when dressing pea seeds before sowing against a pea weevil, no efficiency was observed and the infection of peas with weevils continued during the growing season and during storage [1].

In our experiments, the opposite data was observed. Below are the results of experiments on mung bean cultures. From the results of the experiment it can be seen that in the control variant the infestation results of the experiment on mung bean cultures show that in the control variant the infestation of mung bean seeds was $52.1 \%$, in the variant with Avalanche it was $70 \% \mathrm{dp}$. the infection of mung bean seeds was $3.7 \%$, in the second variant, where the drug Cruiser Extra Cotton 362 c. sus., $3 \mathrm{I} / \mathrm{t}$ was used, $7.4 \%$ of infection was observed.

Table 1

Biological effectiveness of disinfectants against caryopses on mung crops

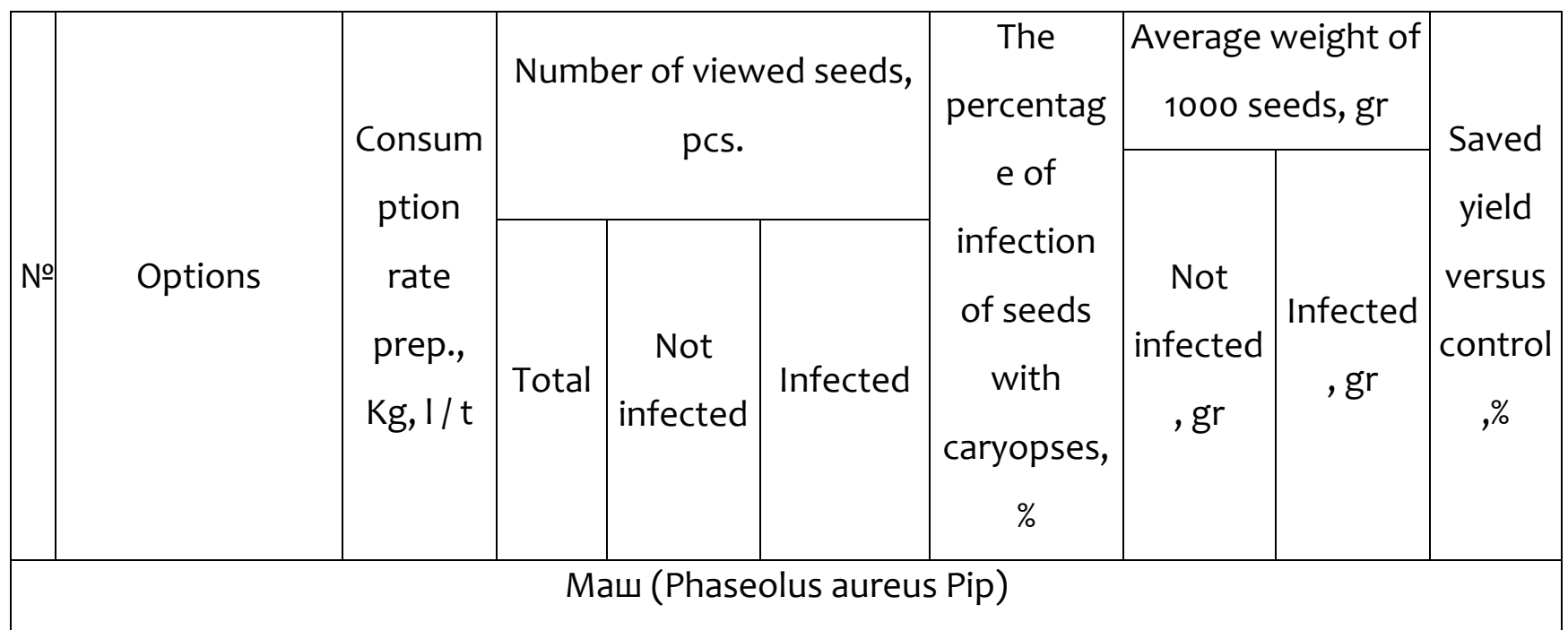


The American Journal of Agriculture and Boimedical Engineering (ISSN - 2689-1018)

Published: November 30, 2020 | Pages: 101-103

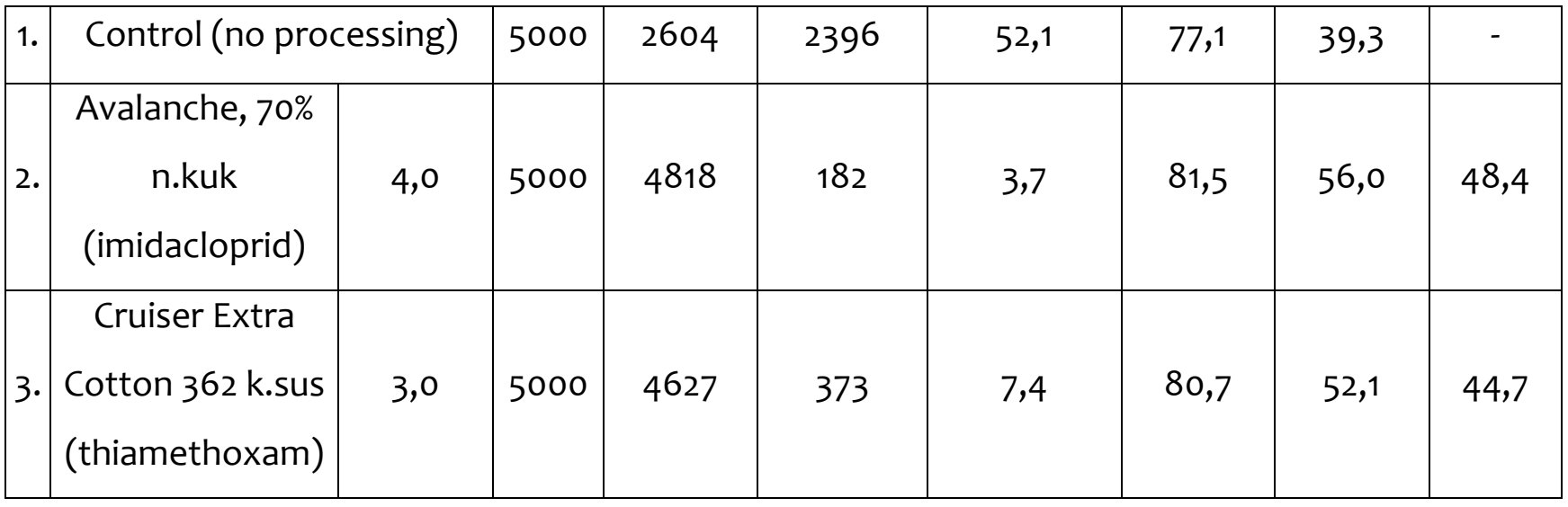

\section{CONCLUSION}

From the results of research work, it can be concluded that the treatment of seeds of leguminous crops with dressing agents 15 days before sowing at the Avalanche consumption rate of $70 \%$ dp. $4 \mathrm{~kg} / \mathrm{t}$ and Cruiser Extra Cotton 362 c. Sous., $31 / \mathrm{t}$, the resulting crop is less infected with caryopses by $48.4 \%$ to $44.7 \%$ than on crops with an untreated plot (control). This method of combating caryopses saves up to $45-50 \%$ of the harvest from bruchuses (caryopses).

\section{REFERENCES}

1. Guidelines for testing insecticides, acaricides and molluscicides in crop production. - Moscow. 1986.-138-139 p.
2.

3.

Pavlov I.F. Agrotechnical method of plant protection. - $M$.: Rosselkhozizdat, 1971. - 206 p.

3. Robert P. Doss, William $M$. Response of $\mathrm{Np}$ mutant of pea (Pisumsativum L.) to pea weevil (Bruchuspisorum L.) oviposition and extracts. Proebsting, Sandra W. Potter, Stephen L. Clement. Journal of Chemical Ecology, January 1995, Volume 21, Issue 1, pp 97-106.

Weisser Wolfgang W., Braendle Christian, Minoretti Nicole. Acyrthosiphon pisum - Predator induced morphological shift in the pea aphid // Proc. Roy. Soc. London. B. - 1999.-No. 1424.C.1175-1181. 